\title{
ANALISA KINERJA PELAYANAN KERETA LIGHT RAIL TRANSIT \\ RUTE A-B PALEMBANG DENGAN METODE RAILQUAL DAN QUALITY FUNCTION DEMAND LAMPUNG, LAMPUNG
}

\author{
Alex Kurniawan effendi ${ }^{1}$ \\ ${ }^{1}$ Program Studi Teknik Sipil, Fakultas Teknik, Universitas Bandar Lampung, \\ Indonesia \\ Email: Alexkurniawan310598@gmail.com
}

\begin{abstract}
ABSTRAK
A rapid development has resulted in the level of urbanization in several big cities getting more advanced. transportation needs will be very important for the community, especially Palembang City, South Sumatra region. Transportation is a means to facilitate the movement of an object from one place to another. PT KAI is a monopoly company without equal participants, so this research is important to conduct research for that. target vision with case studies on LRT (Light Rail Transit) passengers.

The research was conducted by means of a survey to see the performance of the LRT Train (Light Rail Transit). The object of the survey is the people who are on the LRT (Light Rail Transit) train at DJKA-Bumi Sriwijaya station. The data obtained were then processed with the SPSS software program.

1. Djka Station - Sriwijaya Earth Station The significant variable R Square indicates that the value of $\mathrm{R}$ Square is 0.965 . This value illustrates that the variables X1, X2, X3, X4, X5, X6, $\mathrm{X} 10$ on passenger satisfaction are $96.5 \%$ in the model proposed in this study.

2. Djka Station - Sriwijaya Earth Station The significant variable R Square shows that the value of R Square is 0.969 . This value illustrates that the contribution of the variables $\mathrm{X} 1, \mathrm{X} 2, \mathrm{X} 3$, $\mathrm{X} 4, \mathrm{X} 7, \mathrm{X} 8$ to passenger satisfaction is $96.9 \%$ in the model proposed in this study.

3. Djka Station - Sriwijaya Earth Station Significant variable R Square obtains an R Square value of 0.973 . This value illustrates that the contribution variable $\mathrm{X} 1, \mathrm{X} 2, \mathrm{X} 3, \mathrm{X} 4$ to passenger satisfaction is $97.3 \%$ in the model proposed in this study.
\end{abstract}

Keywords: Performance of LRT (Light Rail Transit), significant value, coefficient determination. 


\section{PENDAHULUAN}

Transportasi memegang peranan penting dan strategis dalam mendukung terlaksananya berbagai kegiatan, diantaranya adalah kegiatan pelayanan, perekonomian, pariwisata, dan lain sebagainya. Peranan transportasi dalam kehidupan sehari-hari dapat dilihat dari pergerakan masingmasing orang menuju tempat yang mereka inginkan pada waktu tertentu dan demikian seterusnya. Peran transportasi yang cukup besar perlu ditunjang dengan adanya peningkatan kualitas pelayanan yang memadai. Sementara itu Eksistensi angkutan umum di Palembang ini semakin hari semakin berkurang karena bertambahnya jumlah kendaraan pribadi. Masyarakat sekarang lebih senang menggunakan kendaraan pribadi dari pada angkutan umum. Kurangnya minat masyarakat terhadap jasa angkutan umum sekarang membuat angkutan umum tidak begitu menarik dikarenakan kurang nya kenyamanan dan pelayanan yang baik. Kepuasan penumpang dapat tercapai apabila kualitas pelayanan yang diberikan dapat dipenuhi oleh penyedia jasa transportasi baik milik pemerintah maupun milik swasta.

Transportasi berperan sebagai penunjang, pendorong dan penggerak bagi pertumbuhan daerah dalam upaya peningkatan dan pemerataan pembangunan dan hasil-hasil nya. Salah satu alat transportasi yang efektif bagi masyarakat adalah LRT (Light Rail Transit) Menyadari peranan transportasi darat khususnya pelayanan di dalam LRT (Light Rail Transit) harus seimbang dengan tingkat kebutuhan dan tersedianya pelayanan angkutan yang murah, aman, cepat, lancar, tertib ,teratur.

LRT (Light Rail Transit) merupakan Lintas Rel Terpadu Palembang nama resminya LRT Sumatra Selatan adalah sebuah sistem angkutan cepat dengan model Lintas Rel Terpadu yang beroperasi di Palembang yang menghubungkan Komplek Olahraga Jakabaring dengan Bandar Udara Internasional Sultan Mahmud Badaruddin Pembangunan LRT ini difungsikan sebagai sarana transportasi penunjang warga Palembang dan sekitarnya, Setiap rangkaian kereta LRT (Light Rail Transit) mampu mengangkut hingga 722 penumpang: 231 penumpang di gerbong pertama dan ketiga, dan 260 orang di gerbong kedua.
Sementara, kapasitas tempat duduk sebanyak 78 penumpang. Perjalanan LRT (Light Rail Transit) diawali pada jam 08.04 dari Stasiun DJKA dan diakhiri 08.53 di Stasiun Bandara .Rangkaian kereta dapat mengangkut penumpang dari Jakabaring menuju Bandara SMB II dengan waktu tempuh sekitar 30-45 menit.. Perjalanan. Tiap hari ada total 1 kali keberangkatan dari masing masing stasiun. Light Rail Transit ( LRT ) merupakan kereta bersubsidi Tarif sekali angkut penumpang kereta ini sebesar Rp5.000, per penumpang dari stasiun mana saja, kecuali dari Jakabaring ke Bandara SMB II dipatok tarif Rp10.000, per penumpang.

Penelitian ini menganalisis kinerja kereta berdasarkan tingkat kepuasan pelanggan dengan mengidentifikasi karakteristik yang menjadi prioritas utama dalam meningkatkan kinerja serta usulan perbaikannya agar kepuasan pelanggan terpenuhi. Penelitian ini menggunakan metode RAILQUAL, Zone of Tolerence dan Quality Function Development (QFD). Penggunaan metode RAILQUAL digunakan karena karakteristik pada metode ini di karenakan sesuai dengan kondisi objek penelitian yaitu kereta LRT (Light Rail Transit). Pemilihan metode Zone of Tolerance dikarenakan metode ini dapat memberikan informasi bagian mana yang memerlukan perbaikan. Sedangkan pemilihan metode QFD digunakan untuk melengkapi metode ZOT, yaitu memberikan usulan perbaikan kepada perusahaan secara lebih detail. Dengan penelitian ini diharapkan peneliti dapat memberikan masukan kepada pihak perusahaan sehingga dapat dilakukan upaya perbaikan dan peningkatan kualitas layanan jasa terhadap pelanggan dengan alternatif - alternatif penyelesain masalah yang ada. 


\section{METODOLOGI PENELITIAN}

Pengertian Metode Penelitian adalah tata cara bagaimana suatu penelitian akan dilaksanakan. Metode penelitian ini sering dikaitkan dengan prosedur penelitian atau teknik penelitian. Hal ini disebabkan karena ketiga hal tersebut saling berhubungan dan sulit dibedakan. Metode penelitian membicarakan megenai tata cara pelaksanaan penelitian, sedangkan prosedur penelitian membicarakan alat-alat yang digunakan dalam mengukur atau mengumpulkan data penelitian. Dengan demikian, metode penelitian melingkupi prosedur penelitian dan teknik penelitian. Metode penelitian merupakan tahap penelitian yang dilakukan dalam menyelesaikan suatu masalah, sehingga penelitian yang dilakukan menjadi terarah dalam proses pemecahan masalah. (Nasir 2008).

Dalam penelitian ini penulis akan mengkaji mengenai pelayanan, keamanan, dan kenyamanan masyarakat pengguna angkutan kereta LRT ( Light Rail transit) dan yang digunakan dalam penelitian ini yaitu di lokasi stasiun DJKA.

\section{Lokasi penelitian}

Penelitian ini dilakukan pada angkutan Gerbong Kereta LRT (Light Rail Transit) Kota Palembang dengan Trayek Stasiun DJKA - Stasiun Bumi Sriwijaya pada bulan Desember 2020 Selama 5 Hari.

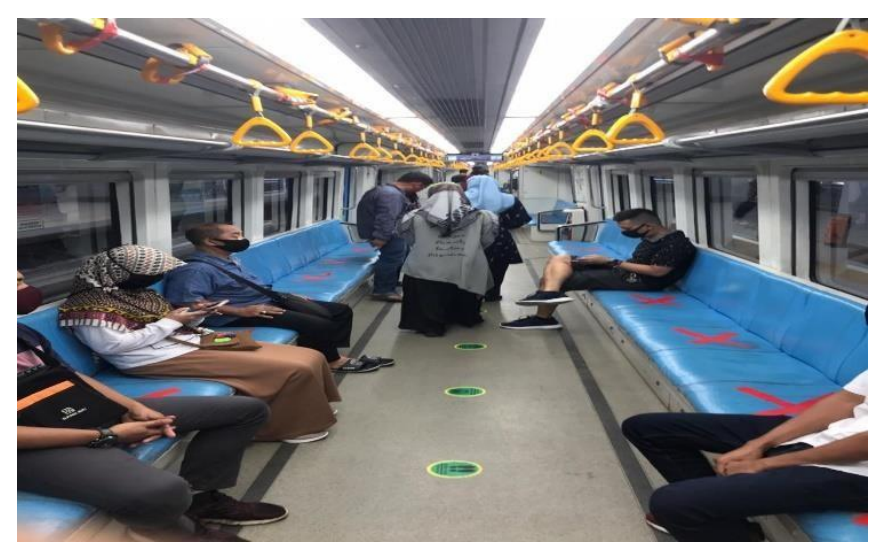

Gambar 1 dalam Gerbong kereta LRT (Light Rail Transit)

\section{Waktu penelitian}

Selama 3 hari yaitu hari Jum'at ,27 November 2020 - Minggu,29 November 2020.

\section{Analisa Data}

Data yang digunakan dalam penelitian ini adalah data primer dan data sekunder dimana data primer didapat dengan cara memberikan kuesioner kepada responden sebagai pengguna jasa angkutan Kereta LRT (Light Rail Transit) dan mewawancara langsung kepada pengelola jasa angkutan, dan data sekunder didapat dari data yang telah tersedia pada instansi terkait yaitu Balai Pengelola Kereta Api Ringan Sumatera Selatan, dan dari situs-situs internet yang berkenaan dengan penelitian. Berdasarkan sumbernya, data dapat dibagi dua yaitu :

1. Data Primer

Data primer adalah data yang langsung diperoleh dari obyek penelitian di lapangan. Data primer yang dibutuhkan dalam penelitian ini antara lain :

a. Karakteristik penumpang.

Dilakukan dengan memberikan formulir yang berisi nama, jenis kelamin, umur, dan jenis pekerjaan.

b. Pelayanan Kereta LRT (LIGHT RAIL TRANSIT)

Dilakukan dengan memberikan formulir yang berisi pertanyaan mengenai:

$>$ Ketersediaan Petunjuk Informasi Pada

Kereta LRT (Light Rail Transit)?

$>\quad$ Ketersediaan Disabilitas Kereta LRT

(Light Rail Transit) bersikap sopan?

$>\quad$ Apakah Kereta LRT (Light Rail Transit) menyediakan P3k?

$>\quad$ Bagaimanakah Kondisi Ruang Tunggu Kereta LRT (Light Rail Transit)?

Bagaimanakah Kondisi Toilet Kereta LRT (Light Rail Transit) ? 
c. Kenyamanan Kereta LRT (Light Rail Transit)

Dilakukan dengan memberikan formulir yang berisi pertanyaan mengenai:

A Apakah Harga Memenuhi Standart Subsidi?

$>$ Bagaimanakah Akses Menuju Stasiun?

> Apakah Kondisi Ketersediaan Fasilitas?

$>$ Bagaimanakah Kondisi Ketersediaan Parkir?

- Bagaimana Kondisi Penerangan dalam stasiun?

d. Keamanan Kereta LRT (Light Rail Transit)

Dilakukan dengan memberikan formulir yang berisi pertanyaan mengenai:

> Bagaimanakah Kondisi Ketersediaan Palu Pemecah Kaca di Kereta LRT (Light Rail Transit)?

Bagaimanakah Ketersediaan Kondisi Keadaan Darurat di Kereta LRT (Light Rail Transit)?

$>$ Bagaimana goncangan selama perjalanan di kereta LRT (Light Rail Transit)?

$>$ Bagaimanakah Ketersediaan Alat Pemadam Api Ringan (APAR)?

$>$ Apakah Ketersediaan Pengangan Tangan (hand grip) di Gerbong Kereta LRT (Light Rail Transit)?

2. Data Sekunder

Data sekunder adalah data yang bukan diusahakan sendiri oleh peneliti. Data yang diperoleh tidak secara langsung dari obyek penelitian tetapi dari pihak lain yang mempunyai informasi data yang diperlukan atau data dari literatur yang berhubungan dengan obyek penelitian, misalanya dari jurnal, buku, internet dan publikasi lainnya. Pada penelitian ini data sekunder diperoleh dari Studi Pustaka, yaitu penelitian yang menggunakan teori - teori dari penggunaan teknik metode RAILQUAL, Zone Of Tolerance (ZOT) , Quality Function Deployment (QFD) yang pernah dilakukan pada penelitian terdahulu serta bidang ilmu lain yang berhubungan.

\section{HASIL DAN PEMBAHASAN}

Sesuai dengan maksud dan tujuan penelitian ini dilakukan yaitu untuk mengetahui terkait pelayanan, kenyamanan dan keamanan yang ada di dalam gerbong LRT (Light Rail Transit). Berikut pembahasan di tinjau dari data kuesioner yang diperoleh dari para penumpang LRT (light Rail Transit).

\section{PELAYANAN \\ Uji Normalitas}

Uji normalitas pada model regresi digunakan untuk menguji apakah nilai residual yang dihasilkan dari regresi terdistribusi secara normal atau tidak. Nilai residual adalah selisih antara nilai perkiraan (predicted value) dengan nilai pengamatan sebenarnya. Model regresi yang baik adalah yang memiliki nilai residual yang terdistribusi secara normal. Beberapa metode uji normalitas yaitu dengan melihat penyebaran data pada sumber diagonal pada Grafik Normal $Q-Q$ Plot of regression standardized residual. Pada penelitian ini yang akan ditinjau data mengenai pelayanan, kenyamanan, dan keamanan yang sesuai menurut responden, karena data tersebut yang menjadi tinjauan khusus dalam penelitian ini.

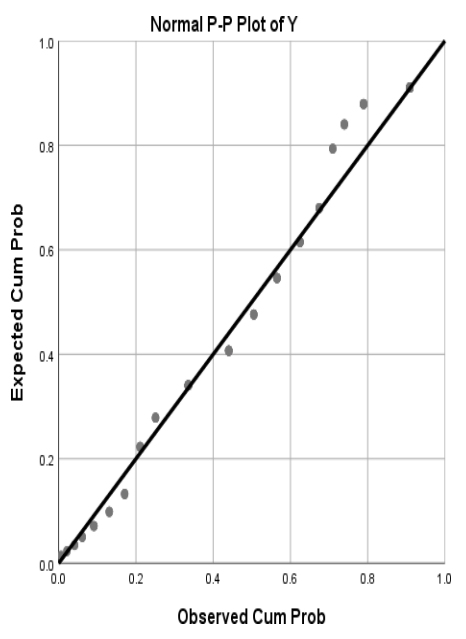

Gambar 2 Uji Normalitas P Plot

Sumber: Data primer yang diolah dengan SPSS, 2021

Dari gambar grafik di atas dapat diketahui bahwa titik-titik menyebar sekitar garis dan mengikuti garis diagonal maka nilai residual tersebut telah normal. Berjumlah 100 data dengan masingmasing 10 pertanyaan. Gambar tersebut menunjukan bahwa data sudah terdistribusi secara sempurna hal itu bisa dlihat dari titik titik yang mengikuti pola linier tersebut.

\section{Uji Correlations}

Analisis korelasi adalah metode evaluasi statistik yang dipergunakan untuk mempelajari kekuatan hubungan antara dua variabel kontinu yang diukur 
secara numerik, oleh karena itulah jenis analisis khusus ini berguna ketika seorang peneliti ingin menetapkan apakah ada kemungkinan hubungan antar variabel penelitian.

Jadi di table dibawah kenapa yang di ambil uji korelasi di antaranya : X1,X2,X3,X4,X5,X6,X10 dikarenakan bahwa titik-titik menyebar sekitar garis dan mengikuti garis diagonal maka nilai residual tersebut telah normal, sedangkan X7,X8,X9 kenapa tidak ada dikarenakan titik-titik tersebut tidak mengikuti garis diagonal.

Signifikan apabila memenuhi persyaratan sebagai berikut :

1. Korelasi yang signifikan ditandai dengan adanya tanda $(*)$ atau $(* *)$ pada data.

2. Tanda $(*)$ atau $(* *)$ pada data terjadi apabila angka pada "Sig. (2-tailed)" pervariabel bernilai dibawah 0,01 (1\%) atau 0,05 (5\%). Jika korelasi signifikan pada $1 \%$ maka sudah pasti juga signifikan pada 5\%, tetapi jika signifikan pada $5 \%$ belum tentu signifikan pada level $1 \%$.

\section{a. X1}

$\mathrm{X} 1$ adalah simbol dari pertanyaan mengenai Ketepatan waktu Kereta LRT. Nilai korelasinya adalah $0,723 * *$ dengan signifikansi $0,00,<0,05$ yang berarti X1 mempunyai nilai yang signifikan terhadap indikator pelayanan.

b. $\mathrm{X} 2$

$\mathrm{X} 2$ adalah simbol dari pertanyaan Petugas Kereta LIGHT RAIL TRANSIT (LRT) bersikap sopan, Nilai korelasinya adalah $0,775^{* *}$ dengan signifikansi $0,00,<0,05$ yang berarti X2 mempunyai nilai yang signifikan terhadap indikator pelayanan.

c. X3

X3 adalah simbol dari pertanyaan Kereta LIGHT RAIL TRANSIT (LRT) menyediakan Fasilitas Kesehatan. Nilai korelasinya adalah $0,762 * *$ dengan signifikansi $0,00,<0,05$ yang berarti X3 mempunyai nilai yang signifikan terhadap indikator pelayanan.

d. $\mathrm{X} 4$

X4 adalah simbol dari pertanyaan mengenai Petugas Kereta LIGHT RAIL TRANSIT (LRT) bersedia untuk membantu Penumpang. Nilai korelasinya adalah $0,786^{* *}$ dengan signifikansi $0,00,<0,05$ yang berarti $\mathrm{X} 4$ mempunyai nilai yang signifikan terhadap indikator pelayanan.

e. X5
X5 adalah simbol dari pertanyaan Petugas Kereta LIGHT RAIL TRANSIT (LRT) selalu berpakaian Rapi \& Bersih, Nilai korelasinya adalah $0,800^{* *}$ dengan signifikansi $0,00,<0,05$ yang berarti X5 mempunyai nilai yang signifikan terhadap indikator pelayanan.

f. X6

X6 adalah simbol dari pertanyaan Petugas Kereta LIGHT RAIL TRANSIT (LRT) bersikap professional. Nilai korelasinya adalah $0,762 * *$ dengan signifikansi $0,00,<0,05$ yang berarti X6 mempunyai nilai yang signifikan terhadap indikator pelayanan.

g. X10

X10 adalah simbol dari pertanyaan Petugas melakukan respon yang baik terhadap penumpang disabilitas ( keterbatasan fisik ). Nilai korelasinya adalah $0,704 * *$ dengan signifikansi $0,00,<0,05$ yang berarti X10 mempunyai nilai yang signifikan terhadap indikator pelayanan.

\section{Analisis Regresi Linier}

Analisis regresi linier adalah sebuah alat statistik yang memberikan penjelasan tentang pola hubugan (model) antara dua variable atau lebih. Analisis regresi linier sederhana merupakan salah satu metode regresi yang dapat dipakai untuk menentukan sebuah variabel bebas (independen) terhadap varibel terikat (dependen) secara lengkap dapat dilihat pada tabel 1. sebagai berikut.

\section{UJI F / ANOVA}

Uji $F$ bertujuan untuk mengetahui ada atau tidaknya pengaruh simultan (bersama-sama) yang diberikan variabel bebas $\mathrm{X}$ terhadap Variabel terikat (Y).

Adapun dasar pengambilan keputusan untuk Uji F

1. Jika nilai sig $<0,05$ atau Uji F, maka terdapat pengaruh pengaruh variabel $\mathrm{X}$ secara simultan terhadap variabel Y.

Tabel 1 UJI F / ANOVA

\begin{tabular}{|c|c|c|c|c|c|c|}
\hline \multicolumn{7}{|c|}{ ANOVA $^{\mathrm{a}}$} \\
\hline \multicolumn{2}{|c|}{ Model } & $\begin{array}{l}\text { Sum of } \\
\text { Squares }\end{array}$ & df & $\begin{array}{l}\text { Mean } \\
\text { Square }\end{array}$ & $\mathrm{F}$ & Sig. \\
\hline 1 & Regression & 3091,789 & 7 & 441,684 & 360,715 & $.000^{\mathrm{b}}$ \\
\hline & Residual & 112,651 & 92 & 1,224 & & \\
\hline & Total & 3204,440 & 99 & & & \\
\hline
\end{tabular}

Sumber: Data primer yang diolah dengan SPSS, 2021 
Berdasarkan output di atas diketahui nilai probabilitas (signifikan) untuk pengaruh $\mathrm{X} 1, \mathrm{X} 2, \mathrm{X} 3, \mathrm{X} 4, \mathrm{X} 5, \mathrm{X} 6, \mathrm{X} 10$ secara simultan terhadap Y adalah sebesar $0,000<0,005$ dan nilai F 360,715 sehingga dapat disimpulkan bahwa terdapat pengaruh $\mathrm{X} 1, \mathrm{X} 2, \mathrm{X} 3, \mathrm{X} 4, \mathrm{X} 5, \mathrm{X} 6, \mathrm{X} 10$ secara simultan terhadap Y ( Pelayanan ).

( Uji F = 360,715 dengan Signifikan 100\% )

\section{COEFFICIENTS / MODEL Y}

Tabel 2 COEFFICIENTS MODEL Y

\begin{tabular}{|c|c|c|c|c|c|}
\hline \multicolumn{6}{|c|}{ Coefficients $^{\mathrm{a}}$} \\
\hline \multirow[b]{2}{*}{ Model } & \multicolumn{2}{|c|}{$\begin{array}{c}\text { Unstandardiz } \\
\text { ed } \\
\text { Coefficients }\end{array}$} & \multirow{2}{*}{$\begin{array}{c}\text { Standardi } \\
\text { zed } \\
\begin{array}{c}\text { Coefficien } \\
\text { ts }\end{array} \\
\text { Beta }\end{array}$} & \multirow[b]{2}{*}{$\mathrm{t}$} & \multirow[b]{2}{*}{ Sig. } \\
\hline & B & $\begin{array}{l}\text { Std. } \\
\text { Error }\end{array}$ & & & \\
\hline $\begin{array}{ll}\text { Y } & \text { (Consta } \\
& \text { nt) }\end{array}$ & $\begin{array}{c}1,55 \\
3\end{array}$ & $\begin{array}{c}0,86 \\
1\end{array}$ & & $\begin{array}{c}1,80 \\
5\end{array}$ & $\begin{array}{c}0,07 \\
4\end{array}$ \\
\hline $\mathrm{X} 1$ & $\begin{array}{c}1,27 \\
9\end{array}$ & $\begin{array}{c}0,23 \\
2\end{array}$ & 0,188 & $\begin{array}{c}5,51 \\
7\end{array}$ & $\begin{array}{c}0,00 \\
0\end{array}$ \\
\hline $\mathrm{X} 2$ & $\begin{array}{c}1,00 \\
4\end{array}$ & $\begin{array}{c}0,32 \\
3\end{array}$ & 0,119 & $\begin{array}{c}3,10 \\
4\end{array}$ & $\begin{array}{c}0,00 \\
3\end{array}$ \\
\hline X3 & $\begin{array}{c}1,49 \\
1\end{array}$ & $\begin{array}{c}0,19 \\
5\end{array}$ & 0,212 & $\begin{array}{c}7,63 \\
2\end{array}$ & $\begin{array}{c}0,00 \\
0\end{array}$ \\
\hline$X 4$ & $\begin{array}{c}1,05 \\
8\end{array}$ & $\begin{array}{c}0,23 \\
1\end{array}$ & 0,141 & $\begin{array}{c}4,57 \\
7\end{array}$ & $\begin{array}{c}0,00 \\
0\end{array}$ \\
\hline X5 & $\begin{array}{c}1,57 \\
0\end{array}$ & $\begin{array}{c}0,25 \\
0\end{array}$ & 0,202 & $\begin{array}{c}6,27 \\
7\end{array}$ & $\begin{array}{c}0,00 \\
0\end{array}$ \\
\hline $\mathrm{X} 6$ & $\begin{array}{c}1,14 \\
7\end{array}$ & $\begin{array}{c}0,24 \\
6\end{array}$ & 0,139 & $\begin{array}{c}4,66 \\
0\end{array}$ & $\begin{array}{c}0,00 \\
0\end{array}$ \\
\hline $\mathrm{X} 10$ & $\begin{array}{c}2,08 \\
2\end{array}$ & $\begin{array}{c}0,17 \\
3\end{array}$ & 0,282 & $\begin{array}{c}12,0 \\
15\end{array}$ & $\begin{array}{c}0,00 \\
0\end{array}$ \\
\hline
\end{tabular}

a. Dependent Variable: $Y$

Sumber: Data primer yang diolah dengan SPSS, 2021

Diketahui nilai constanta (a) sebesar 0,155 sedangkan nilai X1,X2, X3, X4,X5,X6,X10 (b/Koefisien regresi) sebesar 0.127, 0.100, 0.149, $0,105,0,157,0,114,0,208$ sehingga persamaan regresinya dapat ditulis:

\section{COEFFICIENTS}

$$
\begin{aligned}
& Y=X 1+X 2+X 3+X 4+X 5+X 6+ \\
& X 10 \\
& 0,115=X 1(0,128)+X 2(0,100)+X 3 \\
& (0,149)+X 4(0,106)+X 5(0,157)+X 6 \\
& (0,114)+X 10(0,208)
\end{aligned}
$$

\section{R SQUARE}

Koefisien determinasi $\left(\mathrm{R}^{2}\right)$ pada intinya mengukur seberapa jauh kemampuan model dalam menerangkan variasi variabel dependen. Nilai koefisien determinasi adalah antara nol dan satu. Nilai koefisien determinasi dapat dilihat pada tabel dibawah ini:

Tabel 3 R SQUARE

\begin{tabular}{l|c|c|c|c|}
\hline \multicolumn{5}{|c|}{ Model Summary ${ }^{\mathbf{b}}$} \\
\hline Model & $\mathrm{R}$ & $\begin{array}{c}\mathrm{R} \\
\text { Square }\end{array}$ & $\begin{array}{c}\text { Adjusted } \\
\mathrm{R} \\
\text { Square }\end{array}$ & $\begin{array}{c}\text { Std. } \\
\text { Error of } \\
\text { the } \\
\text { Estimate }\end{array}$ \\
\hline 1 & $.982^{\mathrm{a}}$ & 0,965 & 0,962 & 1,10656 \\
\hline
\end{tabular}
a. Predictors: (Constant), X10, X1, X6, X3, X4,
X5, X2
b. Dependent Variable: $Y$

Sumber: Data primer yang diolah dengan SPSS, 2021

Nilai $\mathrm{R}^{2}$ dapat dilihat pada Tabel 4.14 Hasil pengolahan data menunjukan bahwa nilai $R$ Square sebesar 0,965 Nilai tersebut menggambarkan bahwa sumbangan variabel ,X1, $\mathrm{X} 2, \mathrm{X} 3, \mathrm{X} 4, \mathrm{X} 5, \mathrm{X} 6, \mathrm{X} 10$ terhadap kepuasan penumpang adalah sebesar $96,5 \%$ dalam model yang diajukan dalam penelitian ini.

\section{KENYAMANAN}

\section{Uji Normalitas}

Uji normalitas pada model regresi digunakan untuk menguji apakah nilai residual yang dihasilkan dari regresi terdistribusi secara normal atau tidak. Nilai residual adalah selisih antara nilai perkiraan (predicted value) dengan nilai pengamatan sebenarnya. Model regresi yang baik adalah yang memiliki nilai residual yang terdistribusi secara normal. Beberapa metode uji normalitas yaitu dengan melihat penyebaran data pada sumber diagonal pada Grafik Normal $Q-Q$ Plot of regression standardized residual. Pada penelitian ini yang akan ditinjau data mengenai 
pelayanan, kenyamanan, dan keamanan yang sesuai menurut responden, karena data tersebut yang menjadi tinjauan khusus dalam penelitian ini.

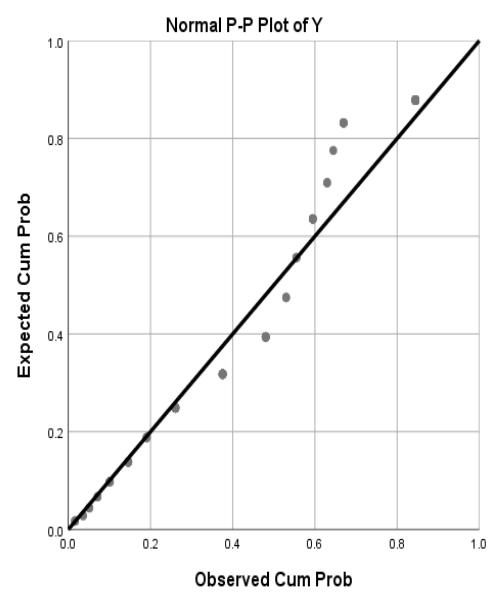

Gambar 3 Uji Normalitas P Plot

Sumber: Data primer yang diolah dengan SPSS, 2021

Dari gambar grafik di atas dapat diketahui bahwa titik-titik menyebar sekitar garis dan mengikuti garis diagonal maka nilai residual tersebut telah normal. Berjumlah 100 data dengan masingmasing 8 pertanyaan. Gambar tersebut menunjukan bahwa data sudah terdistribusi secara sempurna hal itu bisa dlihat dari titik titik yang mengikuti pola linier tersebut.

\section{Uji Correlations}

Analisis korelasi adalah metode evaluasi statistik yang dipergunakan untuk mempelajari kekuatan hubungan antara dua variabel kontinu yang diukur secara numerik. Misalnya tinggi dan berat, oleh karena itulah jenis analisis khusus ini berguna ketika seorang peneliti ingin menetapkan apakah ada kemungkinan hubungan antar variabel penelitian.

Jadi di table dibawah kenapa yang di ambil uji korelasi di antaranya : $\mathrm{X} 1, \mathrm{X} 2, \mathrm{X} 3, \mathrm{X} 4, \mathrm{X} 5, \mathrm{X} 6, \mathrm{X} 7, \mathrm{X} 8$ dikarenakan bahwa titik-titik menyebar sekitar garis dan mengikuti garis diagonal maka nilai residual tersebut telah normal.

1. Korelasi yang signifikan ditandai dengan adanya tanda $(*)$ atau $(* *)$ pada data.

2. Tanda $(*)$ atau $(* *)$ pada data terjadi apabila angka pada "Sig. (2-tailed)" pervariabel bernilai dibawah 0,01 (1\%) atau 0,05 (5\%). Jika korelasi signifikan pada $1 \%$ maka sudah pasti juga signifikan pada 5\%, tetapi jika signifikan pada $5 \%$ belum tentu signifikan pada level $1 \%$.

a. X1

$\mathrm{X} 1$ adalah simbol dari pertanyaan mengenai Tempat duduk nyaman dan bersih. Nilai korelasinya adalah $0,845^{* *}$ dengan signifikansi $0,00,<0,05$ yang berarti X1 mempunyai nilai yang signifikan terhadap indikator Kenyamanan.

b. X2

$\mathrm{X} 2$ adalah simbol dari pertanyaan mengenai Suhu (temperatur) dikereta nyaman, Nilai korelasinya adalah $0,829 * *$ dengan signifikansi $0,00,<0,05$ yang berarti X2 mempunyai nilai yang signifikan terhadap indikator Kenyamanan.

c. X3

X3 adalah simbol dari pertanyaan mengenai kemudahan untuk naik turun penumpang. Nilai korelasinya adalah $0,786^{* *}$ dengan signifikansi $0,00,<0,05$ yang berarti X3 mempunyai nilai yang signifikan terhadap indikator Kenyamanan.

d. X4

X4 adalah simbol dari pertanyaan mengenai Fasilitas penyandang cacat sudah memadai. Nilai korelasinya adalah $0,784 * *$ dengan signifikansi $0,00,<0,05$ yang berarti $\mathrm{X} 4$ mempunyai nilai yang signifikan terhadap indikator Kenyamanan.

e. X5

X5 adalah simbol dari pertanyaan mengenai Fasilitas kesehatan mudah ditemukan, Nilai korelasinya adalah $0,806^{* *}$ dengan signifikansi $0,00,<0,05$ yang berarti X5 mempunyai nilai yang signifikan terhadap indikator Kenyamanan.

f. X6

X6 adalah simbol dari pertanyaan mengenai Bagasi penyimpanan barang sudah mencukupi. Nilai korelasinya adalah $0,801 * *$ dengan signifikansi $0,00,<0,05$ yang berarti X6 mempunyai nilai yang signifikan terhadap indikator Kenyamanan.

g. $\mathrm{X} 7$

X7 adalah simbol dari pertanyaan mengenai Fasilitas keamanan dan keselamatan telah memadai, Nilai korelasinya adalah $0,854 * *$ dengan signifikansi $0,00,<0,05$ yang berarti X7 mempunyai nilai yang signifikan terhadap indikator Kenyamanan. 
h. X8

X8 adalah simbol dari pertanyaan mengenai Penerangan dalam stasiun kereta telah memadai Nilai korelasinya adalah $0,814^{* *}$ dengan signifikansi $0,00,<0,05$ yang berarti X8 mempunyai nilai yang signifikan terhadap indikator Kenyamanan.

\section{Analisis Regresi Linier}

Analisis regresi linier adalah sebuah alat statistik yang memberikan penjelasan tentang pola hubugan (model) antara dua variable atau lebih. Analisis regresi linier sederhana merupakan salah satu metode regresi yang dapat dipakai untuk menentukan sebuah variabel bebas (independen) terhadap varibel terikat (dependen).

\section{UJI F / ANOVA}

Uji $\mathrm{F}$ bertujuan untuk mengetahui ada atau tidaknya pengaruh simultan (bersama-sama) yang diberikan variabel bebas $\mathrm{X}$ terhadap Variabel terikat (Y).

Adapun dasar pengambilan keputusan untuk Uji F 1. Jika nilai sig $<0,05$ atau Uji $F$, maka terdapat pengaruh variabel $\mathrm{X}$ secara simultan terhadap variabel Y.

\begin{tabular}{|c|c|c|c|c|c|}
\hline \multicolumn{6}{|c|}{ ANOVA $^{a}$} \\
\hline Model & $\begin{array}{c}\text { Sum of } \\
\text { Square } \\
\text { s }\end{array}$ & $d f$ & $\begin{array}{l}\text { Mean } \\
\text { Squar } \\
\text { e }\end{array}$ & $F$ & Sig. \\
\hline $\begin{array}{l}1 \text { Regressi } \\
\text { on }\end{array}$ & $\begin{array}{r}2280,57 \\
7\end{array}$ & 6 & $\begin{array}{r}380,09 \\
6\end{array}$ & $\begin{array}{r}485,47 \\
7\end{array}$ & $\begin{array}{r}.000 \\
b\end{array}$ \\
\hline Residual & 72,813 & 93 & 0,783 & & \\
\hline Total & $\begin{array}{r}2353,39 \\
0\end{array}$ & 99 & & & \\
\hline
\end{tabular}

Sumber: Data primer yang diolah dengan SPSS, 2021

Berdasarkan output di atas diketahui nilai probabilitas (signifikan) untuk pengaruh $\mathrm{X} 1, \mathrm{X} 2, \mathrm{X} 3, \mathrm{X} 4, \mathrm{X} 5, \mathrm{X} 6, \mathrm{X} 7, \mathrm{X} 8$ secara simultan terhadap $Y$ adalah sebesar $0,000<0,005$ dan nilai F 485,477 sehingga dapat disimpulkan bahwa dapat pengaruh dari $\mathrm{X} 1, \mathrm{X} 2, \mathrm{X} 3, \mathrm{X} 4, \mathrm{X} 5, \mathrm{X} 6, \mathrm{X} 7, \mathrm{X} 8$ secara simultan terhadap Y ( Kenyamanan ).

( Uji F = 485,47 dengan Signiikan 100\% )

\section{COEFFICIENTS / MODEL Y}

Tabel 5 COEFFICIENTS / MODEL Y

\begin{tabular}{|c|c|c|c|c|c|}
\hline \multicolumn{6}{|c|}{ Coefficients $^{a}$} \\
\hline \multirow[b]{2}{*}{ Model } & \multicolumn{2}{|c|}{$\begin{array}{c}\text { Unstandardiz } \\
\text { ed } \\
\text { Coefficients }\end{array}$} & \multirow{2}{*}{$\begin{array}{c}\begin{array}{c}\text { Standardiz } \\
\text { ed } \\
\text { Coefficient } \\
\text { s }\end{array} \\
\text { Beta }\end{array}$} & \multirow[b]{2}{*}{$t$} & \multirow[b]{2}{*}{ Sig. } \\
\hline & $\mathrm{B}$ & $\begin{array}{l}\text { Std. } \\
\text { Error }\end{array}$ & & & \\
\hline $\begin{array}{ll}1 & \text { (Consta } \\
\text { nt) }\end{array}$ & $\begin{array}{r}1,07 \\
8\end{array}$ & $\begin{array}{r}0,64 \\
4\end{array}$ & & $\begin{array}{r}1,67 \\
3\end{array}$ & $\begin{array}{r}0,09 \\
8\end{array}$ \\
\hline $\mathrm{X} 1$ & $\begin{array}{r}1,29 \\
7\end{array}$ & $\begin{array}{r}0,21 \\
9\end{array}$ & 0,200 & $\begin{array}{r}5,93 \\
1\end{array}$ & $\begin{array}{r}0,00 \\
0\end{array}$ \\
\hline $\mathrm{X} 2$ & $\begin{array}{r}1,14 \\
0\end{array}$ & $\begin{array}{r}0,24 \\
0\end{array}$ & 0,156 & $\begin{array}{r}4,74 \\
4 \\
\end{array}$ & $\begin{array}{r}0,00 \\
0 \\
\end{array}$ \\
\hline X3 & $\begin{array}{r}0,82 \\
1\end{array}$ & $\begin{array}{r}0,19 \\
0\end{array}$ & 0,125 & $\begin{array}{r}4,31 \\
7\end{array}$ & $\begin{array}{r}0,00 \\
0\end{array}$ \\
\hline X4 & $\begin{array}{r}1,65 \\
7\end{array}$ & $\begin{array}{r}0,15 \\
4\end{array}$ & 0,271 & $\begin{array}{r}10,7 \\
87\end{array}$ & $\begin{array}{r}0,00 \\
0\end{array}$ \\
\hline$X 7$ & $\begin{array}{r}1,80 \\
5\end{array}$ & $\begin{array}{r}0,19 \\
1\end{array}$ & 0,279 & $\begin{array}{r}9,47 \\
4\end{array}$ & $\begin{array}{r}0,00 \\
0\end{array}$ \\
\hline X8 & $\begin{array}{r}1,02 \\
3\end{array}$ & $\begin{array}{r}0,20 \\
0\end{array}$ & 0,150 & $\begin{array}{r}5,11 \\
2\end{array}$ & $\begin{array}{r}0,00 \\
0\end{array}$ \\
\hline
\end{tabular}

a. Dependent Variable: $Y$

Sumber: Data primer yang diolah dengan SPSS, 2021

Diketahui nilai constanta (a) sebesar 0,107 sedangkan nilai $\mathrm{X} 1, \mathrm{X} 2, \mathrm{X} 3, \mathrm{X} 4, \mathrm{X} 7, \mathrm{X} 8$ (b/Koefisien regresi) sebesar 0.129, 0.114, $0.082,0,165,0,180,0,102$ sehingga persamaan regresinya dapat ditulis:

\section{COEFFICIENTS}

$$
\begin{aligned}
& Y=X 1+X 2+X 3+X 4+X 7+X 8 \\
& 0,107=X 1(0,129)+X 2(0,114)+X 3 \\
& (0,082)+X 4(0,165)+X 7(0,180)+X 8 \\
& (0,102)
\end{aligned}
$$

\section{R SQUARE}

Koefisien determinasi $\left(\mathrm{R}^{2}\right)$ pada intinya mengukur seberapa jauh kemampuan model dalam menerangkan variasi variabel dependen. Nilai koefisien determinasi adalah antara nol dan satu. Nilai koefisien determinasi dapat dilihat pada tabel 4.13 dibawah ini: 
Tabel 6 R SQUARE

\begin{tabular}{|l|l|c|c|c|}
\hline \multicolumn{5}{|c|}{ Model Summary } \\
\hline & & R & $\begin{array}{c}\text { Adjusted } \\
\text { R } \\
\text { Square }\end{array}$ & $\begin{array}{c}\text { Std. } \\
\text { Error of } \\
\text { the } \\
\text { Estimate }\end{array}$ \\
\hline 1 & $\mathrm{R}$ & Square & Squar \\
\hline
\end{tabular}

a. Predictors: (Constant), X8, X4, X3, X7, X2, X1

Sumber: Data primer yang diolah dengan SPSS, 2021

Nilai $\mathrm{R}^{2}$ dapat dilihat pada Tabel 4.13 Hasil pengolahan data menunjukan bahwa nilai $\mathrm{R}$ Square sebesar 0,969 Nilai tersebut menggambarkan bahwa sumbangan variabel, X1, $\mathrm{X} 2, \mathrm{X} 3, \mathrm{X} 4, \mathrm{X} 7, \mathrm{X} 8$ terhadap kepuasan penumpang adalah sebesar 96,9\% dalam model yang diajukan dalam penelitian ini.

\section{KEAMANAN}

\section{Uji Normalitas}

Uji normalitas pada model regresi digunakan untuk menguji apakah nilai residual yang dihasilkan dari regresi terdistribusi secara normal atau tidak. Nilai residual adalah selisih antara nilai perkiraan (predicted value) dengan nilai pengamatan sebenarnya. Model regresi yang baik adalah yang memiliki nilai residual yang terdistribusi secara normal. Beberapa metode uji normalitas yaitu dengan melihat penyebaran data pada sumber diagonal pada Grafik Normal $Q-Q$ Plot of regression standardized residual. Pada penelitian ini yang akan ditinjau data mengenai pelayanan, kenyamanan, dan keamanan yang sesuai menurut responden, karena data tersebut yang menjadi tinjauan khusus dalam penelitian ini.

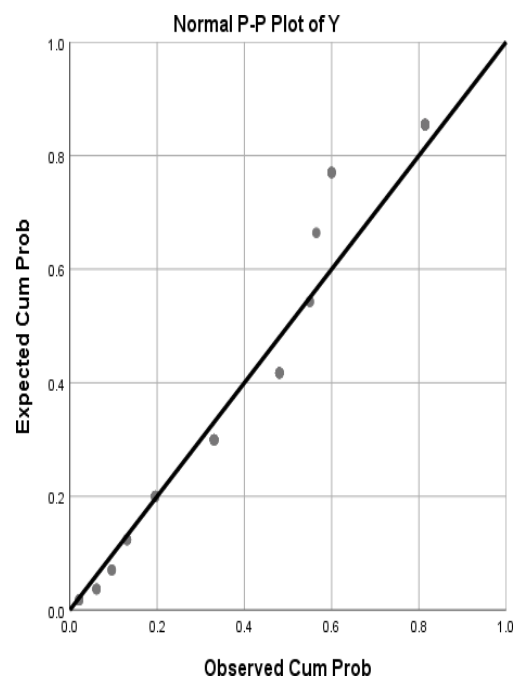

Gambar 4 Uji Normalitas P Plot

Sumber: Data primer yang diolah dengan SPSS, 2021

Dari gambar grafik di atas dapat diketahui bahwa titik-titik menyebar sekitar garis dan mengikuti garis diagonal maka nilai residual tersebut telah normal. Berjumlah 100 data dengan masingmasing 5 pertanyaan. Gambar tersebut menunjukan bahwa data sudah terdistribusi secara sempurna hal itu bisa dlihat dari titik titik yang mengikuti pola linier tersebut.

\section{Uji Correlations}

Analisis korelasi adalah metode evaluasi statistik yang dipergunakan untuk mempelajari kekuatan hubungan antara dua variabel kontinu yang diukur secara numerik. oleh karena itulah jenis analisis khusus ini berguna ketika seorang peneliti ingin menetapkan apakah ada kemungkinan hubungan antar variabel penelitian.

1. Korelasi yang signifikan ditandai dengan adanya tanda (*) atau (**) pada data.

2. Tanda $(*)$ atau $(* *)$ pada data terjadi apabila angka pada "Sig. (2-tailed)" pervariabel bernilai dibawah 0,01 (1\%) atau $0,05(5 \%)$. Jika korelasi signifikan pada $1 \%$ maka sudah pasti juga signifikan pada $5 \%$, tetapi jika signifikan pada $5 \%$ belum tentu signifikan pada level $1 \%$.

a. X1

$\mathrm{X} 1$ adalah simbol dari pertanyaan mengenai Kondisi Ketersediaan Palu Pemecah Kaca di Kereta LRT (Light Rail Transit), Nilai 
korelasinya adalah $0,877 * *$ dengan signifikansi $0,00,<0,05$ yang berarti X1 mempunyai nilai yang signifikan terhadap indikator Keamanan.

b. $\mathrm{X} 2$

$\mathrm{X} 2$ adalah simbol dari pertanyaan mengenai Ketersediaan Kondisi Keadaan Darurat di Kereta LRT (Light Rail Transit), Nilai korelasinya adalah $0,861 * *$ dengan signifikansi $0,00,<0,05$ yang berarti X2 mempunyai nilai yang signifikan terhadap indikator Keamanan.

c. X3

$\mathrm{X} 3$ adalah simbol dari pertanyaan mengenai Goncangan selama perjalanan di kereta LRT (Light Rail Transit), Nilai korelasinya adalah $0,870 * *$ dengan signifikansi $0,00,<0,05$ yang berarti X3 mempunyai nilai yang signifikan terhadap indikator Keamanan.

d. $\mathrm{X} 4$

$\mathrm{X} 4$ adalah simbol dari pertanyaan mengenai Ketersediaan Alat Pemadam Api Ringan (APAR), Nilai korelasinya adalah $0,889^{* *}$ dengan signifikansi $0,00,<0,05$ yang berarti $\mathrm{X} 4$ mempunyai nilai yang signifikan terhadap indikator Keamanan.

e. X5

$\mathrm{X} 5$ adalah simbol dari pertanyaan mengenai Ketersediaan Pengangan Tangan (hand grip) di Gerbong Kereta LRT (Light Rail Transit), Nilai korelasinya adalah $0,802 * *$ dengan signifikansi $0,00,<0,05$ yang berarti X5 mempunyai nilai yang signifikan terhadap indikator Keamanan.

\section{Analisis Regresi Linier}

Analisis regresi linier adalah sebuah alat statistik yang memberikan penjelasan tentang pola hubugan (model) antara dua variable atau lebih. Analisis regresi linier sederhana merupakan salah satu metode regresi yang dapat dipakai untuk menentukan sebuah variabel bebas (independen) terhadap varibel terikat (dependen) secara lengkap dapat dilihat pada tabel 4.16. sebagai berikut.

\section{UJI F / ANOVA}

Uji $F$ bertujuan untuk mengetahui ada atau tidaknya pengaruh simultan (bersama-sama) yang diberikan variabel bebas $\mathrm{X}$ terhadap Variabel terikat (Y).

Adapun dasar pengambilan keputusan untuk Uji $\mathrm{F}$

1. Jika nilai sig $<0,05$ atau $F$, maka terdapat pengaruh variabel $\mathrm{X}$ secara simultan terhadap variabel $\mathrm{Y}$. Tabel 7 UJI F / ANOVA

\begin{tabular}{|c|c|c|c|c|c|}
\hline \multicolumn{6}{|c|}{ ANOVA $^{\mathrm{a}}$} \\
\hline Model & $\begin{array}{c}\text { Sum of } \\
\text { Square } \\
\mathrm{S}\end{array}$ & df & $\begin{array}{l}\text { Mean } \\
\text { Square }\end{array}$ & $\mathrm{F}$ & Sig. \\
\hline $\begin{array}{cl}1 & \text { Regressio } \\
\mathrm{n}\end{array}$ & $\begin{array}{r}963,92 \\
0\end{array}$ & 4 & $\begin{array}{r}240,98 \\
0\end{array}$ & $\begin{array}{r}863,22 \\
6\end{array}$ & .000 \\
\hline Residual & 26,520 & $\begin{array}{l}9 \\
5\end{array}$ & 0,279 & & \\
\hline Total & $\begin{array}{r}990,44 \\
0\end{array}$ & $\begin{array}{l}9 \\
9\end{array}$ & & & \\
\hline
\end{tabular}

a. Dependent Variable: $Y$

b. Predictors: (Constant), X4, X2, X3, X1

Sumber: Data primer yang diolah dengan SPSS, 2021

Berdasarkan output di atas diketahui nilai probabilitas (signifikan) untuk pengaruh $\mathrm{X} 1, \mathrm{X} 2, \mathrm{X} 3, \mathrm{X} 4$ secara simultan terhadap $\mathrm{Y}$ adalah sebesar $0,000<0,005$ dan nilai F 863,226sehingga dapat disimpulkan bahwa dapat pengaruh dari $\mathrm{X} 1, \mathrm{X} 2, \mathrm{X} 3, \mathrm{X} 4$ secara simultan terhadap $\mathrm{Y}$ (Kenyamanan).

( Uji F = 863,226 dengan Signiikan 100\% )

\section{COEFFICIENTS / MODEL Y}

Tabel 8 COEFFICIENTS / MODEL Y

\begin{tabular}{|c|c|c|c|c|c|}
\hline \multicolumn{6}{|c|}{ Coefficients $^{a}$} \\
\hline \multirow[b]{2}{*}{ Model } & \multicolumn{2}{|c|}{$\begin{array}{c}\text { Unstandardiz } \\
\text { ed } \\
\text { Coefficients }\end{array}$} & $\begin{array}{c}\text { Standardi } \\
\text { zed } \\
\text { Coefficient } \\
\text { s }\end{array}$ & & \\
\hline & B & $\begin{array}{l}\text { Std. } \\
\text { Erro } \\
r\end{array}$ & Beta & $t$ & Sig. \\
\hline $\begin{array}{ll}1 & \text { (Consta } \\
n t)\end{array}$ & 1,037 & $\begin{array}{r}0,35 \\
9\end{array}$ & & $\begin{array}{r}2,89 \\
1\end{array}$ & $\begin{array}{r}0,00 \\
5\end{array}$ \\
\hline X1 & 1,010 & $\begin{array}{r}0,12 \\
8\end{array}$ & 0,235 & $\begin{array}{r}7,86 \\
9\end{array}$ & $\begin{array}{r}0,00 \\
0\end{array}$ \\
\hline X2 & 1,397 & $\begin{array}{r}0,12 \\
1\end{array}$ & 0,313 & $\begin{array}{r}11,5 \\
40\end{array}$ & $\begin{array}{r}0,00 \\
0\end{array}$ \\
\hline X3 & 1,177 & $\begin{array}{r}0,12 \\
7\end{array}$ & 0,277 & $\begin{array}{r}9,28 \\
1\end{array}$ & $\begin{array}{r}0,00 \\
0\end{array}$ \\
\hline X4 & 1,204 & $\begin{array}{r}0,12 \\
5\end{array}$ & 0,289 & $\begin{array}{r}9,64 \\
1\end{array}$ & $\begin{array}{r}0,00 \\
0\end{array}$ \\
\hline
\end{tabular}

a. Dependent Variable: Y

Sumber: Data primer yang diolah dengan SPSS, 2021 
Diketahui nilai constanta (a) sebesar 0,103 sedangkan nilai X1,X2,X3,X4 (b/Koefisien regresi) sebesar $0.101, \quad 0.139, \quad 0.117,0,120$ sehingga persamaan regresinya dapat ditulis:

\section{COEFFICIENTS}

$$
\begin{aligned}
& Y=X 1+X 2+X 3+X 4 \\
& 0,103=X 1(0,101)+X 2(0,139)+X 3 \\
& (0,117)+X 4(0,120)
\end{aligned}
$$

\section{R SQUARE}

Koefisien determinasi $\left(\mathrm{R}^{2}\right)$ pada intinya mengukur seberapa jauh kemampuan model dalam menerangkan variasi variabel dependen. Nilai koefisien determinasi adalah antara nol dan satu. Nilai koefisien determinasi dapat dilihat pada tabel

\begin{tabular}{|c|c|c|c|c|}
\hline \multicolumn{5}{|c|}{ Model Summary } \\
\hline Model & $\mathrm{R}$ & $\begin{array}{c}R \\
\text { Square }\end{array}$ & $\begin{array}{l}\text { Adjusted R } \\
\text { Square }\end{array}$ & $\begin{array}{l}\text { Std. Error } \\
\text { of the } \\
\text { Estimate }\end{array}$ \\
\hline 1 & $.987^{\mathrm{a}}$ & 0,973 & 0,972 & 0,52836 \\
\hline
\end{tabular}
4.18 dibawah ini:

Tabel 9 R SQUARE

a. Predictors: (Constant), X4, X2, X3, X1

Sumber: Data primer yang diolah dengan SPSS, 2021

Nilai $\mathrm{R}^{2}$ dapat dilihat pada Tabel 4.18 Hasil pengolahan data menunjukan bahwa nilai $\mathrm{R}$ Square sebesar 0,973 Nilai tersebut menggambarkan bahwa sumbangan variabel , X1, X2, X3, X4, terhadap kepuasan penumpang adalah sebesar $97,3 \%$ dalam model yang diajukan dalam penelitian ini.

\section{Kesimpulan}

Berdasarkan hasil penelitian yang dilakukan di LRT (Light Rail Transit) kota Palembang dengan memberikan 100 kuesioner kepada penumpang dengan Trayek Stasiun DJKA - Stasiun Bumi Sriwijaya, hasil dari penelitian ini diperoleh kesimpulan sebagai berikut :
1. Stasiun Djka - Stasiun Bumi Sriwijaya

Variabel-variabelsignifikan terhadapan kepuasan pelayanan yaitu variabel $\mathrm{X} 1, \mathrm{X} 2, \mathrm{X} 3$, $X 4, X 5, X 6, X 10$ dengan model $Y$ nya sebagai berikut :

$\mathrm{Y}=\mathrm{X} 1+\mathrm{X} 2+\mathrm{X} 3+\mathrm{X} 4+\mathrm{X} 5+\mathrm{X} 6+\mathrm{X} 10$ $0,115=\mathrm{X} 1(0,128)+\mathrm{X} 2(0,100)+\mathrm{X} 3(0,149)$ $+\mathrm{X} 4(0,106)+\mathrm{X} 5(0,157)+\mathrm{X} 6(0,114)+\mathrm{X} 10$ (0,208)

Dari pengolahan data $R$ Square menunjukan bahwa nilai $\mathrm{R}$ Square sebesar 0,965 Nilai tersebut menggambarkan bahwa sumbangan variabel, X1, X2, X3, X4,X5,X6,X10 terhadap kepuasan penumpang adalah sebesar 96,5\% dalam model yang diajukan dalam penelitian ini.

2. Stasiun Djka - Stasiun Bumi Sriwijaya

Variabel-variabel signifikan terhadapan kepuasan kenyamanan yaitu variabel $\mathrm{X} 1, \mathrm{X} 2$, $X 3, X 4, X 7, X 8$ dengan model $Y$ nya sebagai berikut :

$\mathrm{Y}=\mathrm{X} 1+\mathrm{X} 2+\mathrm{X} 3+\mathrm{X} 4+\mathrm{X} 7+\mathrm{X} 8$

$0,107=\mathrm{X} 1(0,129)+\mathrm{X} 2(0,114)+\mathrm{X} 3(0,082)$

$+\mathrm{X} 4(0,165)+\mathrm{X} 7(0,180)+\mathrm{X} 8(0,102)$

Dari pengolahan data $\mathrm{R}$ Square menunjukan bahwa nilai $\mathrm{R}$ Square sebesar 0,969 Nilai tersebut menggambarkan bahwa sumbangan variabel , X1, X2, X3, X4, X7, X8 terhadap kepuasan penumpang adalah sebesar 96,9\% dalam model yang diajukan dalam penelitian ini.

3. Stasiun Djka - Stasiun Bumi Sriwijaya

Variabel-variabel signifikan terhadapan kepuasan keamanan yaitu variabel X1, X2, X3, $X 4$ dengan model $Y$ nya sebagai berikut :

$\mathrm{Y}=\mathrm{X} 1+\mathrm{X} 2+\mathrm{X} 3+\mathrm{X} 4$

$0,103=\mathrm{X} 1(0,101)+\mathrm{X} 2(0,139)+\mathrm{X} 3(0,117)$

$+\mathrm{X} 4(0,120)$

Dari pengolahan data R Square menunjukan bahwa nilai $\mathrm{R}$ Square sebesar 0,973 Nilai tersebut menggambarkan bahwa sumbangan variabel, X1, X2, X3, X4, terhadap kepuasan penumpang adalah sebesar $97,3 \%$ dalam model yang diajukan dalam penelitian ini. 


\section{Saran}

Berdasarkan proses dan hasil penelitian yang telah dilakukan dalam pembuatan Tugas Akhir ini, maka dapat diberikan saran-saran sebagai berikut:

1. Model regresi yang diperoleh dari penelitian ini supaya dapat digunakan sebagai referensi untuk menentukan kinerja pelayanan, keanyamanan, dan keamanan Kereta LRT (Light Rail Transit).

2. Untuk penelitian selanjutnya, disarankan peneliti dapat meneliti variabel lain yang dapat mempengaruhi kepuasan konsumen, seperti persepsi harga dan lokasi. Hal tersebut bertujuan agar penelitian selanjutnya dapat bermanfaat bagi peneliti dan perusahaan. Tindakan yang dilakukan untuk meningkatan kinerja Kereta LRT (Light Rail Transit) adalah sebagai berikut :

a. Petugas Kereta LRT (Light Rail Transit) Bersedia Untuk Membantu Konsumen.

b. Petugas Kereta LRT (Light Rail Transit) Dapat Di Percaya Mengenai Masalah Pelayanan.

c. Kemudahan Naik Turun Penumpang.

d. Fasilitas Penyandang Cacat Sudah Memadai.

e. Fasilitas Kesehatan Mudah Ditemukan.

\section{DAFTAR USTAKA}

Arikunto, 2000, Prosedur Penelitian Suatu Pendekatan Praktek. Jakarta : Rineka Cipta Clarkson H.Oglesby, 1999, Alih Bahasa, Teknik Jalan Raya Jilid 1, Jakarta : Gramedia.

Hadihardaja dkk, 1997, Sistem Transportasi. Jakarta : Universitas Guru Darma.

Kotler Philip 1997. Manajemen Pemasaran. Edisi Bahasa Indonesia jilid satu. Jakarta : Prentice Hall.

Kerlinger, 1973, Multiple Regression in Behavioural Research. New York : Holt, Rineheart \& Winston, Inc.

Martin, 2004, Sarana sanitasi Perkotaan, Jakarta : Ekamitra Engineering.

Nasir, 2008, Metodologi Penelitian, Jakarta : PT Rosda Karya.

Roscoe, 1975, Fundamental research statistics for the Behavioural Sciences, New York : Holt Rineheart \& Winston.
Slovin, 1960, dalam Pengambilan Sampel, Populasi, Sampling, Buku Metologi Penelitian

Sugiyono, 2011, Metode Penelitian Kuantitatif Kualitatif dan $R \& D$.

Bandung : Alfabeta.

Tamin, 2000, Perencanaan dan Permodelan Transportasi. Bandung, Indonesia : Penerbit ITB

Uma Sekaran, 2006, Metodologi Penelitian Untuk Bisnis Buku 1 Edisi 4, Jakarta : Salemba Empat

Umar, 2003, Metodologi Penelitian Untuk Skripsi dan Tesis bisnis, Jakarta : PT. Gramedia Pustaka 